\title{
Volatile Substance Abuse: a review of findings in ESPAD 2003 Richard Ives *
}

\begin{abstract}
Volatile substance abuse (VSA) is an under-recognised worldwide problem. Data, especially international comparisons, are limited. The 2005 ESPAD report published data on VSA from 35 countries, collected in 2003. Lifetime prevalence of VSA can be as high as 22 per cent, with little difference between boys and girls in most countries. Perceived risk of VSA is worryingly low (comparable to perceived risk of cannabis), varies greatly between countries, and does not seem to be related to levels of use within countries. Neither is perceived availability of volatile products related to national prevalence rates of misuse.
\end{abstract}

International comparisons must be approached with caution, but this report gives useful data on an under-researched issue.

\section{Introduction}

Volatile Substance Abuse (VSA) is the misuse of substances such as gases, glues and aerosols (as well as, less commonly, a range of other substances) to achieve intoxication. While much VSA is experimental, it can be deadly, even at the 'experimental' stage of misuse; VSA- related deaths in the UK (for which data has been collected since 1971) exceed 2,000 (Field-Smith et al 2002). In the UK, more teenage deaths are associated with VSA than with illegal drugs and, for some age groups, it is a bigger killer than causes of death such as leukaemia, pneumonia and drowning (ACMD 1995).

It is a worldwide problem (e.g. Ives, 1996a), and can be particularly widespread among some indigenous groups (Ives, 1996b) and among some children living on the street (WHO, 1998). Chronic VSA is associated with poor socio-economic conditions and a range of social and psychological problems (Ives, 2000a; Ives, 1999), and with delinquency and illegal drug use (NSDUH 2005).

Despite the size of the problem, it has received much less attention than illegal drugs and alcohol. However, various 'supply-side' activities have been attempted, including product modification (MacLean and d'Abbs, forthcoming), a number of countries have controls on the sales of products containing 'sniffable' substances, and professionals have been issued with guidance on tackling the topic (e.g. see Ives 2000b).

International survey evidence is also limited, especially time series data. Thus the publication of the Report on the 2003 ESPAD (European school Survey Project on Alcohol and other Drugs), which includes prevalence data on substance misuse including VSA, is a welcome addition to knowledge of the problem (Hibell, et al 2005). ESPAD is a survey of 15- to16-year-old students in 35 European Countries. The organisers of the survey request a minimum of 2,400 students in each country. ${ }^{\dagger}$ Students answer a paper questionnaire administered at school. The 2003 survey is the third of its kind; previous studies took place in 1995 and 1999. The study is co-ordinated by the Swedish Council for Information on Alcohol and

\footnotetext{
* Managing Director, educari Ltd, Manor Farm, Kettlestone, Norfolk, NR21 OAU, UK (email: richard@educari.com)

${ }^{\dagger}$ This was not achieved in all cases.
} 
Other Drugs (CAN) and supported by the Council of Europe Pompidou Group and the Swedish National Institute of Public Health (see www. espad.org).

This paper looks at the published data on VSA in this Report, and makes some observations on the information contained therein. While international comparisons should always be treated with caution (for example, because of possible differences in the ways that the survey was carried out in the different countries), this Report contains much of interest.

\section{Levels of VSA}

In the international report, the term used for VSA is 'inhalants', but the actual question about prevalence which was asked (in the appropriate languages of the countries surveyed, of course) was: 'On how many occasions (if any) have you sniffed a substance (sniffing glue, aerosols, etc) to get high?' It is known that reported prevalence of VSA is quite sensitive to questionnaire wording, and asking about it in different ways produces different results (Ives 1999). There will also be issues of translation and cultural adaptation of the wording. Country comparisons should be therefore treated as indicative rather than definitive.

\section{Lifetime prevalence}

The lifetime experience of VSA (i.e. whether they had ever tried VSA) among students in the 35 countries varied from two per cent (in Romania) to 22 per cent (in Greenland). The UK was (with Iceland) at $10^{\text {th }}$ position, with 12 per cent of students reporting trying VSA. Countries with similar levels to the UK included France (11\%) and Austria (14\%). Table 1 gives a summary.

\section{Table 1 about here}

\section{Sex differences}

There was generally little difference between boys' and girls' lifetime prevalence. Exceptions included Portugal (boys $10 \%$ girls $6 \%$ ), Belgium (boys $9 \%$ girls 5\%), Italy (boys 8\% girls 5\%) and the Ukraine (boys 9\% girls 4\%). In Ireland, the girls reported considerably higher misuse than boys (girls $21 \%$ boys $14 \%$ ). The figures for the UK were boys: 12 per cent, and girls: 13 per cent.

\section{Changes over time}

There had been some changes in prevalence between the three surveys. ${ }^{\dagger}$ In the 1995 survey (when fewer countries were included), UK students reported the highest levels of VSA (20\%), while in the 1999 survey the UK rate, at 15 per cent, was exceeded by Ireland (22\%), Greenland (19\%), and Malta (16\%). ${ }^{\ddagger}$ Between 1999 and 2003, the levels of lifetime prevalence had declined in Ireland (22\% to 18\%), Lithuania (10\%to 5\%) and the UK (15\%to 12\%) (as well as in Ukraine, Norway and Russia (Moscow)), but there had been increases in prevalence in (among other countries) Greenland (19\%to 22\%) and Portugal (3\%to 8\%).

\footnotetext{
* The only other two countries where girls reported using more than boys were the Isle of Man and the Faroe Islands, but in these countries the differences between boys and girls were small.

${ }^{\dagger}$ Because of possible differences in sampling, etc, differences between the three surveys should not be over-interpreted.

${ }^{\ddagger}$ Ireland and Greenland, among others, did not participate in the 1995 survey.
} 


\section{2-month and 30-day prevalence}

Since much VSA is experimental and many of those who try 'sniffing' only do so once or twice, lifetime prevalence can be high while current misuse may be low. As well as measuring lifetime prevalence, the researchers were also able to establish use in the 12 months prior to the survey and in the previous 30 days. VSA in the past 30 days will mean, in most cases, that the respondent is a current misuser. VSA in the past 12 months will, in most cases, indicate experimentation.

The higher figures for use in the last 12 months and in the last 30 days are found in the same countries as those with higher lifetime prevalence. Table 2 shows the results for the 13 countries with the highest lifetime prevalence in 2003 . While, as might be expected, Greenland had the highest 12-month prevalence (16\%), Croatia and Cyprus had the highest 30-day prevalence (6\%).

\section{Table 2 about here}

\section{Perceived risk}

For each of the substances about which prevalence data were collected, students were also asked about the risk of using them. The response categories were: 'no risk'; 'slight risk'; 'moderate risk'; 'great risk'; and 'don't know'. The ESPAD report gives tables showing the percentage of students answering 'great risk' separately for use 'once or twice' and for use 'regularly'. Table 3 has been compiled from these tables and shows data for selected countries (a table giving details for all 35 countries is available from the author on request).

\section{Table 3 about here}

On average, about a third (35\%) of students thought that VSA 'once or twice' posed a great risk, while about two-thirds (68\%) thought that use 'regularly' was a great risk. This compares with an average of 32 per cent who thought that that the risk of using cannabis once or twice was great, an average of 73 per cent who thought that regular ecstasy use would be a great risk, and 81 per cent who thought that regular injections of drugs would be a great risk.

There were considerable variation between countries, with less than a fifth of German students (19\%) seeing a great risk in use 'once or twice', compared to two-thirds (67\%) of Cypriot students. Students in the Czech Republic reported the highest 'great risk' figure for use 'regularly' (85\%), with the lowest being Malta $(55 \%)$.

There were some interesting differences between boys and girls on the two measures. In most countries, girls rated the danger of use 'once or twice' rather lower than boys did. This was true for 27 out of 35 countries, but often the difference was only a few percentage points, giving an average figure of 37 per cent for boys and 34 per cent for girls: a difference of only three per cent. In the UK, the figures were very close to the average for all countries, at 36 per cent for boys and 34 per cent for girls.

But girls consistently rated the dangers of regular use higher than the boys did on average, 72 per cent of girls rated regular use as a 'great risk' compared to only 65 per cent of boys. The only exception was the UK, where boys' and girls' ratings were equal, at 62 per cent. 
As described earlier, there were few sex differences in the prevalence of VSA, but in most countries boys' VSA was higher than girls, apart from Ireland where girls' VSA exceeded boys'. Yet girls in Ireland were similar to other girls in other countries in rating the dangers of regular use higher than boys did $68 \%$ compared to $60 \%$.

\section{Availability of volatile substances}

To gain an idea of how readily available drugs were, the researchers asked the students how easy it was to obtain various substances. The ESPAD report gives tables showing the percentage of students answering that volatile substances were 'very easy' or 'fairly easy' to obtain. Table 4 has been compiled from these tables and shows data for selected countries (a table giving details for all 35 countries is available from the author on request).

\section{Table 4 about here}

Ireland, which had a high prevalence of VSA, had the highest rates of both boys $(83 \%)$ and girls (71\%) saying that volatile substances were very or fairly easy to obtain. The lowest figure was for Romania (13\%), a country with lowest reported prevalence. About half (53\%) of boys and girls in the UK - slightly more girls (55\%) than boys (51\%) - said that volatile substances were very or fairly easy to obtain.

\section{Discussion}

For those concerned about VSA, the ESPAD report contains some interesting indications, although it should be noted that cross-cultural comparisons are fraught with difficulty, and the published data are in summary form only and do not permit detailed analysis. A caveat has already been entered about the sensitivity of reported VSA prevalence to question wording. It should also be noted that ESPAD is a school-based survey and therefore does not include young people who are not in school at the time of the survey. Since school refusers are disproportionately likely to misuse substances the ESPAD figures will probably be underestimates. There may be differences between countries in the degree of under-reporting - for example, a high prevalence of VSA has been reported among Romanian street-children but they are unlikely to be in school and therefore to be included in the survey.

It will be of particular interest to UK readers that there are now nine countries with a higher prevalence than the UK. This is partly because of a decline in reported prevalence in the UK between 1995 and 1999 and (to a lesser extent) between 1999 and $2003 .{ }^{*}$ No country other than the UK specifically monitors VSArelated deaths (Field-Smith et al 2005), but there is no reason to believe that there are not similar numbers of deaths associated with VSA in countries with similar prevalence levels. VSA is a world-wide problem and deserves more attention, especially from those countries with high levels of prevalence.

It is interesting to note that students in Ireland, a country with high prevalence levels, were most likely to say that obtaining volatile substances was very or fairly easy, whereas students in Romania - the country with the lowest

\footnotetext{
* Four countries with higher prevalence levels than the UK in 2003 - Ireland, Greenland, Slovenia and Greece - did not participate in the 1995 survey (nor did Romania, Bulgaria, Russia, Latvia and France); Cyprus, while participating in 1995, did not take part in 1999.
} 
prevalence - were least likely to say this. However, it is important not to jump to the conclusion that easy access leads to increased use. It could be, for example, that the Romanian students didn't know what substances could be misused and so thought that they must be difficult to obtain; or because Romania is a poor country, perhaps the students were referring to the lack of money to buy volatile substances. Nevertheless, these associations are worth further investigation.

The ESPAD report comments that students in Greenland had not heard of many of the drugs which were asked about - and if other drugs are not available this might be an explanation for the higher levels of VSA prevalence in Greenland. If this is the case, then it is an interesting example of the idea that some people will satisfy their desire for intoxication with whatever substance is available. However, as noted previously, 30-day prevalence rates for VSA in Greenland were not the highest, implying, perhaps, that much VSA in Greenland is experimental and short-term only.

It is worrying that only about a third of students considered that trying VSA once or twice was a great risk - a figure very close to that for cannabis. While the message about the dangers of injecting drugs seems to have reached large proportions of young people in most countries, the message about the particular risks of experimental VSA has not got through. In fact, it is likely that in most countries the message has not even been conveyed. Since the UK has around average figures on this measure, it seems that the limited amount of publicity about the dangers of VSA has not had much effect. It is probably not reassuring that assessment of risk seems to bear little relationship to use - the most obvious example being that girls in Ireland are not only more likely than boys to try volatile substances but also to rate their regular use as a great risk.

This paper has included all the VSA-related data given in ESPAD report. Unfortunately, VSA has not been consistently included in the ESPAD questions or analysis. For example, the researchers asked about the first illicit drug that the students had ever used, but did not include volatile substances in their list surprising, because for many this will be (along with alcohol) the first drug tried.*

\section{Acknowledgements}

Thanks to the ESPAD team and Associates for undertaking this important survey. And thanks to John Ramsey, Mike Ashton and anonymous reviewers for advice on an earlier draft of this paper.

\section{References}

ACMD 1995 Volatile Substance Abuse: A Report by the Advisory Council on the Misuse of Drugs HMSO

Field-Smith M E Butland B K Ramsey J D Anderson H R 2002 'Trends in Deaths Associated with the Use of Volatile Substances' St George's, University of London (available on www.sgul.ac.uk/ depts/ phs/ vsamenu.htm) Hibell B et al 2005 The ESPAD Report 2003 Alcohol and Other Drug Use Among Students in 35 European Countries Swedish Council for Information on Alcohol and Other Drugs, CAN, and the Council of Europe Pompidou Group Ives R 1996a Volatile Substance Abuse among young people in Poland Council of Europe Pompidou Group

\footnotetext{
"They didn't ask about alcohol, either.
} 
Ives R 1996b 'Drug use among young Western Australians' J ournal of Substance Misuse (Part 1:) 1, 2; (Part 2:) 1, 41996

Ives R 1999 Volatile Substance Abuse: a report on survey evidence Health

Education Authority

Ives R 2000a 'Disorders relating to the use of volatile substances' in: Gelder The New Oxford Textbook of Psychiatry

Ives R 2000b Volatile Substance Abuse: Guidance for Professionals Health Education Board for Scotland

MacLean $S$ and d'Abbs $P$ 'Will modifying inhalants reduce volatile substance misuse? A Review' Drugs: Education, Prevention and Policy forthcoming NSDUH 2005 Inhalant Use and Delinquent Behaviors among Young Adolescents (the NSDUH Report (USA 'National Survey on Drug User and Health') March 17, 2005) (http:/ / oas. samhsa.gov/ 2k5/ inhale/ inhale. htm (accessed 20-12-2005)) WHO 1998 Volatile Solvents Abuse: A global overview WHO Programme on Substance Abuse

Table 1 Lifetime prevalence of VSA in ESPAD 2003 Survey

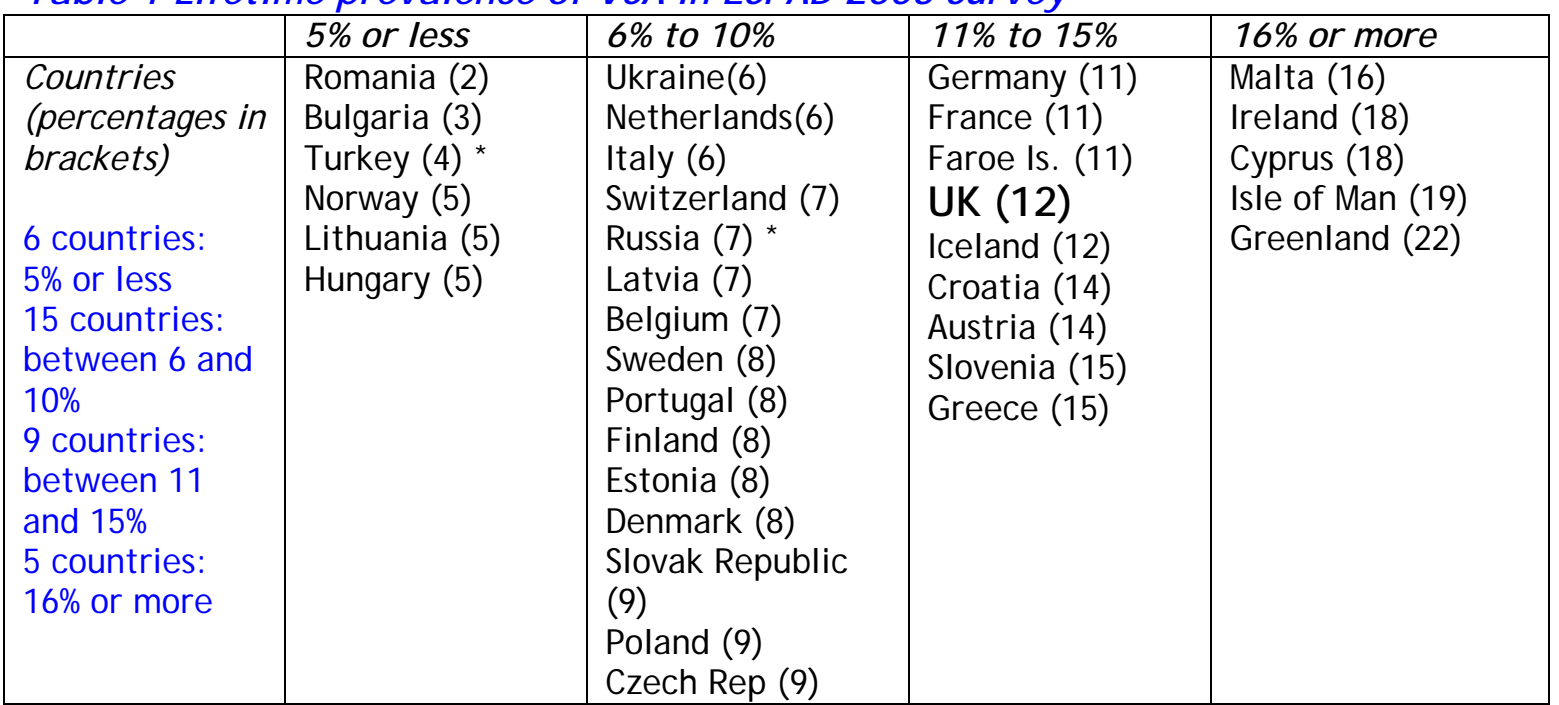

* Turkish survey covered six cities. Russian survey covered Moscow only.

Based on Figures 56a and 56b (page 173) and Table 36c (page 401) in ESPAD 2003 survey report

Table 2 VSA prevalence levels for 13 countries: Lifetime, 12 months, and 30-days

\begin{tabular}{|l|c|c|c|}
\hline \multicolumn{1}{|c|}{ Country } & $\begin{array}{c}\text { Lifetime } \\
\text { prevalence }\end{array}$ & $\begin{array}{c}12 \text { month } \\
\text { prevalence }\end{array}$ & $\begin{array}{c}30 \text { day } \\
\text { prevalence }\end{array}$ \\
\hline France & 11 & 5 & 2 \\
Faroe Is. & 11 & 7 & 2 \\
UK & $\mathbf{1 2}$ & $\mathbf{7}$ & $\mathbf{3}$ \\
Iceland & 12 & 8 & 3 \\
Croatia & 14 & 11 & 6 \\
Austria & 14 & 6 & 3 \\
Slovenia & 15 & 7 & 4 \\
Greece & 15 & 8 & 5 \\
Malta & 16 & 10 & 5 \\
Ireland & 18 & 10 & 3 \\
Cyprus & 18 & 11 & 6 \\
Isle of Man & 19 & 11 & 4 \\
Greenland & 22 & 16 & 4 \\
\hline
\end{tabular}

Based on Figures 56a and 56b (page 173) and Table 36c (page 401) in the ESPAD 2003 survey 
Table 3 Perceived risk of volatile substance abuse (selected countries)

(Percentage answering 'Great risk')

\begin{tabular}{|c|c|c|c|c|c|c|}
\hline Country & \multicolumn{3}{|c|}{ 'Once or twice' } & \multicolumn{3}{|c|}{ 'Regularly' } \\
\hline & boys & girls & total & boys & girls & total \\
\hline Austria & 24 & 17 & 21 & 57 & 65 & 61 \\
\hline Bulgaria & 39 & 36 & 37 & 64 & 73 & 69 \\
\hline Croatia & 40 & 35 & 37 & 61 & 68 & 65 \\
\hline Cyprus & 64 & 74 & 67 & 69 & 75 & 72 \\
\hline Czech Rep. & 43 & 33 & 38 & 82 & 87 & 85 \\
\hline France & 44 & 38 & 41 & 73 & 78 & 76 \\
\hline Germany & 21 & 18 & 19 & 56 & 64 & 60 \\
\hline Greece & 36 & 30 & 33 & 66 & 69 & 68 \\
\hline Hungary & 31 & 29 & 30 & 67 & 74 & 70 \\
\hline Iceland & 54 & 55 & 55 & 77 & 87 & 82 \\
\hline Ireland & 36 & 34 & 35 & 60 & 68 & 64 \\
\hline Italy & 43 & 40 & 41 & 63 & 66 & 65 \\
\hline Lithuania & 58 & 53 & 55 & 74 & 83 & 78 \\
\hline Malta & 27 & 21 & 24 & 53 & 57 & 55 \\
\hline Netherlands & 23 & 19 & 21 & 55 & 62 & 59 \\
\hline Norway & 31 & 26 & 29 & 70 & 79 & 74 \\
\hline Romania & 42 & 45 & 44 & 58 & 68 & 64 \\
\hline Slovenia & 28 & 20 & 24 & 57 & 61 & 59 \\
\hline Sweden & 27 & 24 & 25 & 66 & 72 & 69 \\
\hline UK & 36 & 34 & 35 & 62 & 62 & 62 \\
\hline AVERAGE* & 37 & 34 & 35 & 65 & 72 & 68 \\
\hline
\end{tabular}

Based on Tables 43a, b \& c ESPAD Appendix II page 418-20 in the ESPAD 2003 survey

* of all 35 countries (excluding Greenland)

Table 4 Availability of volatile substances (selected countries)

\begin{tabular}{|l|c|c|c|}
\hline \multicolumn{1}{|c|}{ Country } & \multicolumn{3}{|c|}{$\begin{array}{c}\text { 'Very easy' } \text { 'f 'fairly easy' to obtain: } \\
\text { percentages }\end{array}$} \\
\hline & boys & girls & total \\
\hline Austria & 52 & 60 & 56 \\
\hline Bulgaria & 30 & 34 & 32 \\
\hline Croatia & 47 & 53 & 50 \\
\hline Cyprus & 53 & 51 & 52 \\
\hline Czech Rep & 54 & 42 & 47 \\
\hline France & 36 & 36 & 36 \\
\hline Germany & 60 & 61 & 60 \\
\hline Greece & 47 & 45 & 46 \\
\hline Hungary & 37 & 38 & 37 \\
\hline Iceland & 45 & 44 & 45 \\
\hline Ireland & 83 & 71 & 77 \\
\hline Italy & 17 & 15 & 16 \\
\hline Lithuania & 28 & 29 & 28 \\
\hline Malta & 36 & 42 & 29 \\
\hline Netherlands & 38 & 33 & 36 \\
\hline Norway & 38 & 35 & 37 \\
\hline Romania & 15 & 12 & 13 \\
\hline Slovenia & 57 & 65 & 61 \\
\hline Sweden & 51 & 51 & 51 \\
\hline UK & $\mathbf{5 1}$ & $\mathbf{5 5}$ & $\mathbf{5 3}$ \\
\hline AVERAGE* & 42 & 40 & 41 \\
\hline
\end{tabular}

Based on Figures 58a and 58b (page 179) and Tables 42a, b \& c ESPAD Appendix II page 415-17 in the ESPAD 2003 survey

$*$ of all 35 countries 